\title{
Lactose malabsorption and lactose intolerance in adults - a cause of irritable bowel syndrome?
}

\author{
By Åke Nilsson
}

\begin{abstract}
Gastroenterologists and general practitioners see many patients that have abdominal symptoms which are not explained when the patients are investigated for celiac disese, inflammatory bowel disease, peptic ulcer or tumours. The diagnosis is irritable bowel syndrome (IBS). Many of these patients report intolerance to certain foods including milk, and some develop symptoms after ingestion of lactose during the lactose tolerance test. In Northern European populations, lactose malabsorption is, however, not clearly overrepresented among the adult IBS patients, and subjective lactose intolerance is more common than IBS. Relatively few respond to a lowlactose diet on a long-term basis.

Keywords: Irritable bowel syndrome, lactose intolerance, lactose malabsorption
\end{abstract}

\begin{abstract}
Introduction
Irritable bowel syndrome (IBS) is a common symptomatic diagnosis which is troublesome for the patient. It is characterized by variable abdominal symptoms such as diarrhoea, obstipation, variable stool frequency, abdominal pain and flatulence. The pathogenesis of the disease is poorly known and the available medical therapy far from satisfactory. The severity of the symptoms varies between patients, and with time in the individual patients. In those with the most severe symptoms the condition is an important cause of incapacitation and sick leave. Food intolerance, disturbed intestinal motility and visceral hypersensitivity have been key issues in the hypotheses trying to explain the symptoms. In many of the patients the symptoms are similar to those experienced by some lactose malabsorbers ingesting lactose. The question was therefore raised early, whether lactose malabsorption is an important cause of symptoms and subjective food intolerance in IBS patients (1-3).

This article briefly summarizes some of the current knowledge about the relation between IBS, lactose intolerance and lactose malabsorption in adults seen from the gastroenterologist's point of view.
\end{abstract}

\section{The spectrum of IBS in adults}

The prevalence of IBS in industrialized countries is $12-17 \%$ (4-6). Accordingly the general practitioners and gastroenterologists face a large number of patients with abdominal complaints of various kinds. Some patients have diarrhoea in the sense that bowel movements are frequent and sometimes urgent but without an increase in stool volume. Others suffer from abdominal pain and gaseous distension as the major symptoms. Laboratory tests are normal and no alarm symptoms such as weight loss or bloody stools are present. Upper gastrointestinal endoscopy and colonoscopy and small bowel X-ray are normal. Thus other diagnoses such as inflammatory bowel disease and celiac disease are excluded in the patients with severe symptoms, whereas mild cases do not always need investigation. The symptoms tend to vary with time, which makes good therapeutic studies demanding, positive responses to placebo being frequent. Furthermore different study populations with IBS have been differently selected. A great many patients with abdominal

\footnotetext{
Åke Nilsson, Prof., Dept of Medicine, University Hospital of Lund, SE-221 85 Lund, Sweden. E-mail: Ake.Nilsson@med.lu.se

The article is based on a lecture presented at the meeting Lactose intolerance revisited, Febuary 1-2, 2001, Stockholm, Sweden.
}

complaints of a benign nature do not see a doctor whereas others who are more worried about symptoms with the same severity do. Others have noticed that they react with diarrhoea and abdominal complaints on milk ingestion, and there is large public attention to the possibility of lactose intolerance. Accordingly they may avoid milk ingestion and may become free of symptoms without consulting a doctor. The general practitioner sees IBS patients with varying severity of symptoms, and only those with severe symptoms are referred to a gastroenterologist. Most patient populations with the diagnosis IBS that have been studied have thus been subjected to some kind of selection depending on the clinical context in which they appear. Variations in the selection of the study population as well as variations in the frequency of lactose malabsorption in the background population may thus influence the outcome of studies relating IBS, lactose malabsorption and lactose intolerance.

\section{Studies relating IBS, lactose malabsorption and lactose intolerance}

The prevalence of lactose maldigestion is $17 \%$ in Finland, 15-50\% in Central Europe, and 6-19\% in white Northern Americans (7). A number of recent studies indicate that subjective lactose intolerance is increased in patients with irritable bowel syndrome, despite no increase in the prevalence of lactose malabsorption. Of particular interest is a Finnish study (7) which investigated a cohort of 427 healthy subjects who had previously been investigated with regard to the presence or absence of lactose malabsorption. The subjects were examined for the occurrence of IBS and subjective lactose intolerance. IBS was found in $15 \%$ of both the lactose maldigesters and digesters. One third of the subjects reported intolerance to dairy products containing $20 \mathrm{~g}$ lactose or less. About half of this third were lactose maldigesters and half were lactose digesters. Of the subjects with IBS, the percentage of lactose maldigesters was the same as in the whole study group (24\%) but the number who repored lactose intolerance was higher $(60 \%$ compared with $27 \% \mathrm{p}<0.001)$. The conclusion was that there is a relation between subjective lactose intolerance and IBS rather than with lactose maldigestion. Subjective lactose intolerance was more common in females. Other studies have supported the idea that there is a connection between irritable bowel syndrome (IBS) and lactose intolerance but not necessarily with lactose malabsorption. Suarez et al. (8), showed that 9 of $30(30 \%)$ 
subjects with self-reported severe lactose intolerance had normal lactose-hydrogen breath test. Similarly, Salzman et al. (9) found that 18 of 42 subjects ( $43 \%$ ) with subjective lactose intolerance did not have lactose maldigestion. The cause of subjective lactose intolerance in subjects with adequate lactose digestion is unknown. Many patients have abdominal complaints such as bloating, diarrhoea, and flatulence that are perceived as lactose intolerance due to the public awareness of this factor, but which may be related to other dietary or stress factors.

Some lactose maldigesters can tolerate moderate amounts of lactose in their diet with minimal or no symptoms. Suarez et al. (8) found that 21 subjects with lactose maldigestion had few symptoms when ingesting $240 \mathrm{~mL}$ milk per day for one week (12.1 g lactose). Other reports have made similar findings (10).

Should patients with IBS be routinely investigated for lactose malabsorption? The answer was yes in a Dutch study (11) of 70 Caucasian IBS patients and 35 healthy volunteers (staff members). Of the IBS patients, 17 out of 70 , but only 2 out of 35 of the controls, had lactose malabsorption. The conclusion was that in this population, which was selected from the referral patients at an out-patient gastroenterology unit, some previously unknown lactose malabsorbers were discovered. On the other hand, Hamm et al. (12) examined 1452 patients with an established history of IBS and revealed an incidence of lactose malabsorption comparable to that in the general U.S. population as estimated by the lactose hydrogen breath test. The conclusion was that routine lactose absorption test in IBS patients is not costeffective. Parker et al. (13) examined 122 patients with IBS and found $27 \%$ to have lactose malabsorption. Only nine out of 23 patients with lactose malabsorption improved, however, on a low-lactose diet. The conclusion was that the effect of the low lactose diet was disappointing.

All these studies concern patients from populations with a relatively low background frequency of lactose malabsorption. The experiences from other study populations may be different. Vernia et al. (14), in a study from Italy, examined 503 patients with IBS and 336 patients who identified themselves as milkintolerant found that $67 \%$ of the IBS patients and $71 \%$ of those who considered themselves as intolerant to milk were lactose malabsorbers as estimated by the lactose-hydrogen breath test. Thus lactose malabsorption was so common in both groups that the evaluation of symptoms did not influence the diagnostic workup plan. Goldstein et al. (15), in a study from Israel, examined the absorption of lactose, fructose and sorbitol by the hydrogen breath test, in patients with IBS and functional bowel complaints, found $78 \%$ to be lactose malabsorbers and $73 \%$ to be fructose malabsorbers. This group also reported that half or more of the patients improved on dietary restrictions. The relative role of lactose intolerance and lactose malabsorption in IBS may obviously differ between different populations.

\section{Mechanisms behind IBS}

For detailed discussion of the pathogenesis (16) and pharmacologialc treatment of IBS the reader is referred to other current literature (17-19). There is at present some evidence both for a disturbed motility and an increased visceral hypersensitivity. In a recent paper, powerful propagation contractions were identified in the colon after stimulation with cholecystokinin or with a meal (20). Other studies showed an abnormal propagation pattern of duodenal pressure waves in diarrhoea-predominant IBS (21). In an elegant study by Simrén and co-workers (22) lipids and saline were infused into the duodenum and hormones including motilin, cholecystokinin, pancreatic polypeptide and neuropeptide $\mathrm{Y}$ were measured in healthy controls and in IBS patients. Simultaneously a balloon catheter was inserted in the sigmoid colon and the pain perception threshold and viscero- somatic referral pain were assessed before and after the duodenal infusions. The IBS patients experienced pain at a lower balloon pressure when lipids were given in the duodenum and motilin levels were higher in some IBS patients. The conclusion was that postprandial symptoms in IBS patients may be explained in part by a nutrition-dependent exaggerated sensory component of the gastrocolic response. If so, it is possible that symptoms may be triggered by lactose, and some other dietary components (23) in the IBS patients. Mechanisms that are linked to the visceral hypersensitivity may be evoked either at the duodenal or jejunal level or by gas produced by fermentation in the colon.

\section{Conclusion}

Lactose malabsorption is not a common important factor behind the symptoms in adult IBS patients in Northern European populations. Lactose intoleranse is more common but the results with low-lactose diet as a whole are disappointing. IBS patients may have a visceral hypersensitivity and an intestinal motility pattern that make them react to several dietary components. Further studies of the mechanisms behind these subjective intolerances are needed and further dietary trials that focus attention on the role of incompletely absorbed fermentable carbohydrates are highly warranted.

\section{REFERENCES}

1. Gudmand-Hoyer E, Riis P, Wulff HR: The significance of lactose malabsorption in the irritable colon syndrome. Scand J Gastroenterol 1973; 8:273-8.

2. Newcomer AD, McGill DB: Irritable bowel syndrome. Role of lactase deficiency. Mayo Clin Proc 1983;58:339-41.

3. Gudmand-Hoyer E: The clinical significance of disaccharide maldigestion Am J Clin Nutr 1994:59:735S-741S.

4. Agreus L: The epidemiology of functional gastrointestinal disorders. Eur J Surg Suppl 1998;583:60-6.

5. Talley NJ: Irritable bowel syndrome: definition, diagnosis and epidemiology. Baillieres Best Pract Res Clin Gastroenterol 1999;13:371-84.

6. Taub E, Cuevas JL, Cook EW, 3rd, Crowell M, Whitehead WE: Irritable bowel syndrome defined by factor analysis. Gender and race comparisons. Dig Dis Sci 1995;40:2647-55

7. Vesa TH, Seppo LM, Marteau PR, Sahi T, Korpela R: Role of irritable bowel syndrome in subjective lactose intolerance. Am J Clin Nutr 1998;67:710-5.

8. Suarez FL, Savaiano DA, Levitt MD: A comparison of symptoms after the consumption of milk or lactose-hydrolyzed milk by people with selfreported severe lactose intolerance. N Engl J Med 1995;333:1-4.

9. Saltzman JR, Russell RM, Golner B, Barakat S, Dallal GE, Goldin BR: A randomized trial of Lactobacillus acidophilus $\mathrm{BG} 2 \mathrm{FO} 4$ to treat lactose intolerance. Am J Clin Nutr 1999:69:140-6.

10. Mascolo R, Saltzman JR: Lactose intolerance and irritable bowel syndrome. Nutr Rev 1998;56:306-8

11. Bohmer CJ, Tuynman HA: The clinical relevance of lactose malabsorption in irritable bowel syndrome. Eur J Gastroenterol Hepatol 1996:8:1013-6.

12. Hamm LR, Sorrells SC, Harding JP, et al.: Additional investigations fail to alter the diagnosis of irritable bowel syndrome in subjects fulfilling the Rome criteria. Am J Gastroenterol 1999;94:1279-82.

13. Parker TJ, Woolner JT, Prevost AT, Tuffnell Q, Shorthouse M, Hunter JO: Irritable bowel syndrome: is the search for lactose intolerance justified? Eur J Gastroenterol Hepatol 2001;13:219-25.

14. Vernia P, Di Camillo M, Marinaro V: Lactose malabsorption, irritable bowel syndrome and self-reported milk intolerance. Dig Liver Dis 2001; 33:234-9.

15. Goldstein R, Braverman D, Stankiewicz H: Carbohydrate malabsorption and the effect of dietary restriction on symptoms of irritable bowe syndrome and functional bowel complaints. Isr Med Assoc J 2000;2:583-7.

16. Camilleri M: Functional bowel disease: roles of sensation and motility Schweiz Med Wochenschr 2000;130:1772-81.

17. Camilleri M: Novel medications for the irritable bowel syndrome: motility and sensation. J Pediatr Gastroenterol Nutr 2001;32:S35-7.

18. Camilleri M: Management of the irritable bowel syndrome. Gastroenterology 2001;120:652-68

19. Drossman DA. Review article: an integrated approach to the irritable bowel syndrome. Aliment Pharmacol Ther 1999;13 Suppl 2:3-14

20. Chey WY, Jin HO, Lee MH, Sun SW, Lee KY. Colonic motility abnormality in patients with irritable bowel syndrome exhibiting abdominal pain and diarrhoea. Am J Gastroenterol 2001;96:1499-506.

21. Simren M, Castedal M, Svedlund J, Abrahamsson H, Bjornsson E: Abnormal propagation pattern of duodenal pressure waves in the irritable bowel syndrome (IBD). Dig Dis Sci 2000;45:2151-61.

22. Simren M, Abrahamsson H, Bjornsson ES: An exaggerated sensory component of the gastrocolonic response in patients with irritable bowel syndrome. Gut 2001:48:20-7.

23. Simren M, Mansson A, Langkilde AM, et al.: Food-related gastrointestinal symptoms in the irritable bowel syndrome. Digestion 2001;63:108-15. 